\title{
Cara de Aprender - Uma Ferramenta para Trabalhar Emoções e Aprendizagem Utilizando Expressões Faciais
}

\author{
Carla Marina C. Paxiúba ${ }^{1}$, Celson Pantoja Lima ${ }^{1}$ \\ ${ }^{1}$ Programa de Computação- Universidade Federal do Oeste do Pará (UFOPA) - \\ Santarém, PA - Brasil \\ \{Carla.paxiuba@ufopa.edu.br, celson.lima@ufopa.edu.br\}
}

\begin{abstract}
Nowadays is widely accepted that emotions significantly influence the learning process, but how to recognize the student's emotions, and how to relate the various types of emotions to learning, remains an open question. This article presents a tool that uses the student's emotions to improve the teaching-learning process. Students' facial expressions are automatically obtained through a facial expression recognition tool - Learning Face. Thus, it is possible to establish relationships between facial expressions, emotions, teaching methodologies and student performance.
\end{abstract}

Resumo. Atualmente é amplamente aceito que as emoções influenciam significativamente no processo de aprendizagem, porém, como reconhecer as emoções dos alunos, e, como relacionar os vários tipos de emoções com a aprendizagem, continua a ser uma questão em aberto. Este artigo apresenta uma ferramenta que utiliza as emoções do aluno para melhorar o processo de ensino-aprendizagem. As expressões faciais dos alunos são automaticamente obtidas através de uma ferramenta de reconhecimento de expressões faciais Cara de Aprendizagem - CADAP. Assim, é possível estabelecer relações entre expressões faciais, emoções, metodologias de ensino e desempenho dos estudantes.

\section{Introdução}

Vários estudos apontam que a emoção está constantemente associada ao aprendizado [Damasio,1994]. Entende-se também que as emoções podem influenciar fortemente o conhecimento e os objetivos gerais dos alunos [Piaget, 1989]. A conexão entre aprendizado complexo e emoções tem sido bem documentada em várias disciplinas relacionadas, como psicologia [Vygotsky,1994], educação [Mora, 2013] e ciência da computação [Picard, 1997]. Mora (2013) diz que tudo o que promove a aquisição de conhecimento, como curiosidade, atenção, memória para tomada de decisão, requer a energia que conhecemos como emoção. Detectar problemas relacionados à emoção pode se tornar um trabalho central para o futuro da educação. O trabalho de Izard (1984) mostra que as emoções negativas induzidas prejudicam o desempenho em tarefas cognitivas, e as emoções positivas têm um efeito oposto. Reconhecendo o papel significativo das emoções, Picard (1997) explica a necessidade de monitorar sinais emocionais e como isso está presente com os seres humanos quando ela afirma: 
"Qualquer que seja sua estratégia, o bom professor detecta importantes pistas afetivas do aluno e responde de maneira diferente por causa delas. Por exemplo, o professor pode deixar dicas ou pistas sutis para o aluno descobrir, preservando assim o senso de descoberta autopropulsionada do aprendiz. Se o assunto envolve expressão emocional deliberada, como é o caso da música, ou é um tópico "não emocional" como a ciência, o professor que atende ao interesse, ao prazer e ao sofrimento do aluno é percebido como mais eficaz do que o professor que não faz isso. Bons professores sabem que a frustração geralmente precede o desistir e sabem como redirecionar ou motivar o aluno nesses momentos. Eles conhecem seu aluno, incluindo o quanto de angústia o aluno pode suportar antes de quebrar o aprendizado". No entanto, conhecer todos os alunos e compreender a reação emocional de cada aluno em um ambiente de aprendizagem é uma tarefa complicada e desafiadora.

Mesmo reconhecendo que a emoção é uma parte fundamental de nossa vida cotidiana, ela geralmente tem sido ignorada pela tecnologia ao longo dos anos. Essa falta de qualquer interação emocional, em muitos aspectos, tornou a tecnologia frustrante para os seres humanos. Porém, existem agora pesquisadores especializados em computação afetiva - concentrando suas pesquisas nas novas tecnologias que promovem a compreensão básica da emoção e seu papel na experiência humana. Pesquisadores do Grupo de Pesquisa de Computação Afetiva do MIT realizaram investigações em áreas como: novas maneiras pelas quais as pessoas podem comunicar estados afetivo-cognitivos, novas formas de avaliar indiretamente a frustração, o estresse e o humor, e como os computadores podem ser mais emocionalmente inteligentes, assim como outras áreas similares envolvendo aspectos afetivos. A frase Affective Computing, foi cunhada por Picard, quando ela publicou um livro intitulado Affective Computing in 1997 [Picard, 1997], e o nome tornou-se o termo mais comumente utilizado para esse campo da computação. Em seu livro, ela analisou detalhadamente como imaginava que a computação afetiva progrediria, bem como áreas como possíveis aplicações e possíveis preocupações. Picard argumentou que deveria haver algo como um raciocínio emocional para que houvesse qualquer forma de verdadeira inteligência de máquina. Sua ideia-chave era que deveria ser possível criar máquinas que se relacionassem, se originassem ou influenciassem deliberadamente a emoção e outros fenômenos afetivos. Ela argumentou que os programadores precisavam considerar o efeito ao escrever softwares que interagiam com as pessoas. De acordo com a escola de pensamento de Picard, as emoções (que também são conhecidas como afetos) são estados identificáveis, que podem ser modelados para possibilitar, como humanos, as possíveis interações entre pessoas e máquinas. Claro, que algumas emoções são mais difíceis de detectar do que outras, e, é por isso, que Ekman (1978) considerou que havia apenas seis emoções universais tornadas óbvias pela expressão facial - raiva, nojo, medo, felicidade (alegria), tristeza e surpresa. Posteriormente acrescentou o desprezo.

Considerando todas as questões abordadas acima, este trabalho propõe o desenvolvimento de um software para reconhecer emoções dos alunos a partir de suas expressões faciais e usar essas emoções no processo de ensino-aprendizagem, assim apoiando o desenvolvimento de uma metodologia de ensino que considere as emoções dos alunos em todo seu processo. Sendo assim a seção 2 apresenta uma metodologia de 
ensino baseada em emoções, a seção 3 a ferramenta que suporta esta metodologia e a seção 4 as considerações finais do trabalho.

\section{Considerando as expressões dos alunos no processo de ensino para verificação de emoções- Uma abordagem metodológica}

Conforme abordado na seção anterior, psicólogos e pedagogos têm apontado como as emoções podem interferir positivamente (quando o aluno está motivado e sentindo emoções positivas) e negativamente (quando o aluno está mal-humorado e deprimido por exemplo) na aprendizagem de um aluno. Dessa forma este trabalho propõe a utilização de uma abordagem metodológica que utiliza as emoções dos alunos para melhorar o processo de ensino - aprendizagem, e, para isto, dentre outras coisas, utiliza o suporte tecnológico de uma ferramenta - CADAP - de captura de expressões faciais dos estudantes durante as aulas, para que posteriormente possam ser feitos correlações entre as expressões faciais dos estudantes, as emoções, e a aprendizagem dos conteúdos.

\section{1 - A Proposta}

A abordagem proposta neste trabalho prevê a utilização de uma ferramenta - CADAP para captura de expressões faciais dos alunos durante as aulas. Esta ferramenta captura as expressões dos alunos e as classificar em sete tipos distintos de emoções: alegria, tristeza, surpresa, medo, desprezo, desgosto e raiva. A captura é feita em intervalos de tempo pré-definidos pelo docente, e, ao final da aula é emitido um relatório por discente, que apresenta as emoções que predominaram a cada intervalo de tempo. Esta abordagem prevê um processo composto de cinco etapas conforme figura 1 .

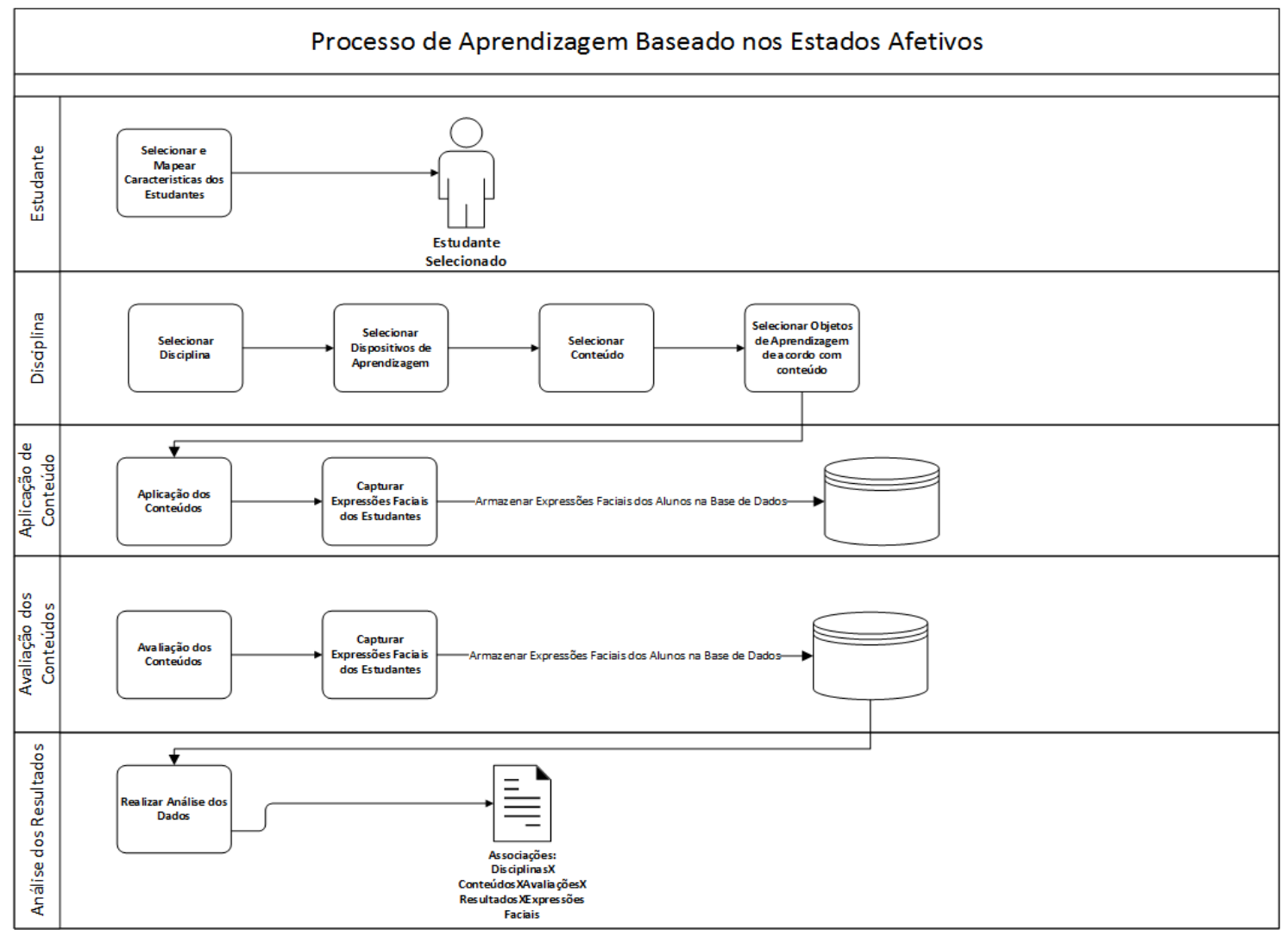

Figura 1 - Abordagem Metodológica de Ensino Baseada na Emoção dos Alunos 
Neste processo o primeiro passo deve ser a seleção e categorização dos alunos que participarão das aulas que utilizarão a ferramenta. Posteriormente o docente deve preparar aulas que serão visualizadas na ferramenta, fazendo a seleção dos conteúdos que serão apresentados e dos objetos de aprendizado que serão utilizados. Os alunos assistirão as aulas na ferramenta e enquanto visualizam as aulas e respondem questionamentos sobre o conteúdo, serão filmados e suas expressões faciais serão capturada e correlacionadas com as sete emoções básicas que a ferramenta trabalha alegria, tristeza, surpresa, desgosto, raiva, medo, desprezo e compromisso. Todas as informações geradas serão mantidas em uma base de dados e utilizadas para posterior geração de correlações das emoções, desempenho dos alunos, objetos de aprendizagem utilizados, conteúdos apresentados, entre outros. Nas próximas seções será realizada o detalhamento de cada etapa do processo.

\subsection{1 - Etapa 1 - Modelagem do Perfil do Estudante}

Um perfil do aluno é composto por um conjunto de propriedades que caracterizam o estudante como: sua identificação pessoal, suas características pessoais e sociais, seu perfil de aprendizagem, seu conhecimento sobre determinados assuntos, etc. Algumas informações relativas ao perfil do aluno, como sua identificação pessoal, preferências pessoais e sociais, são raramente modificadas. Em contrapartida, informações que envolvem aspectos cognitivos como seu estilo de aprendizagem e seu conhecimento sobre um dado assunto, são constantemente alterados. Além disto, as informações sobre os aspectos cognitivos estão diretamente relacionadas ao ambiente e ao escopo de aprendizagem, fazendo com que seja necessário a ocorrência de alterações dentro deste contexto. [Dolog, 2005], [Lee, 2005].

Uma questão fundamental dentro da área de modelagem do aluno é determinar como construir modelos concisos que representem da melhor forma os aspectos cognitivos de um aluno em relação ao ambiente em que este se encontra. Um dos pontos é identificar qual estilo de aprendizagem está associado ao aluno para que seja possível traçar o perfil de aprendizagem do mesmo. No escopo deste trabalho será adotado o modelo de Felder e Silverman (1988) para classificar os alunos em relação a seu perfil de aprendizagem. Os autores propuseram um modelo de estilos de aprendizagem considerando métodos de ensino que pudessem atender tais estilos. Segundo Felder e Silverman (1988) um aluno pode ser classificado por um conjunto de estilos de aprendizagem. Isto porque cada um dos estilos descritos observa uma dimensão diferente do comportamento do aluno durante a aprendizagem.

Baseado no trabalho de Felder e Silverman (1988) foi criado um instrumento chamado índice de Estilos de Aprendizagem que é utilizado para determinar as preferências nas quatro dimensões (ativo/reflexivo, sensorial/intuitivo, visual/verbal e seqüêncial/global). Na utilização do Índice de Estilos de Aprendizagem, o usuário deverá estar atento para dois pontos importantes: 1. Os resultados fornecem uma indicação das preferências individuais de aprendizagem e, provavelmente, uma indicação ainda melhor do perfil de preferências de um grupo de estudantes (por exemplo, uma turma), mas eles devem ser utilizados com cautela. 2. O perfil do estilo de aprendizagem de um estudante fornece uma indicação dos prováveis pontos fortes e possíveis tendências ou hábitos que poderiam estar conduzindo a dificuldades na vida acadêmica. O primeiro passo ao utilizar a abordagem metodológica proposta neste 
trabalho é utilizar este formulário (figura 2) para classificar os alunos de acordo com seu estilo de aprendizagem baseado no instrumento. O objetivo de realizar esta classificação na metodologia é possibilitar futuras análises que possam correlacionar o perfil de aprendizagem dos alunos, as emoções expressadas e o desempenho dos discentes nas avaliações dos conteúdos.

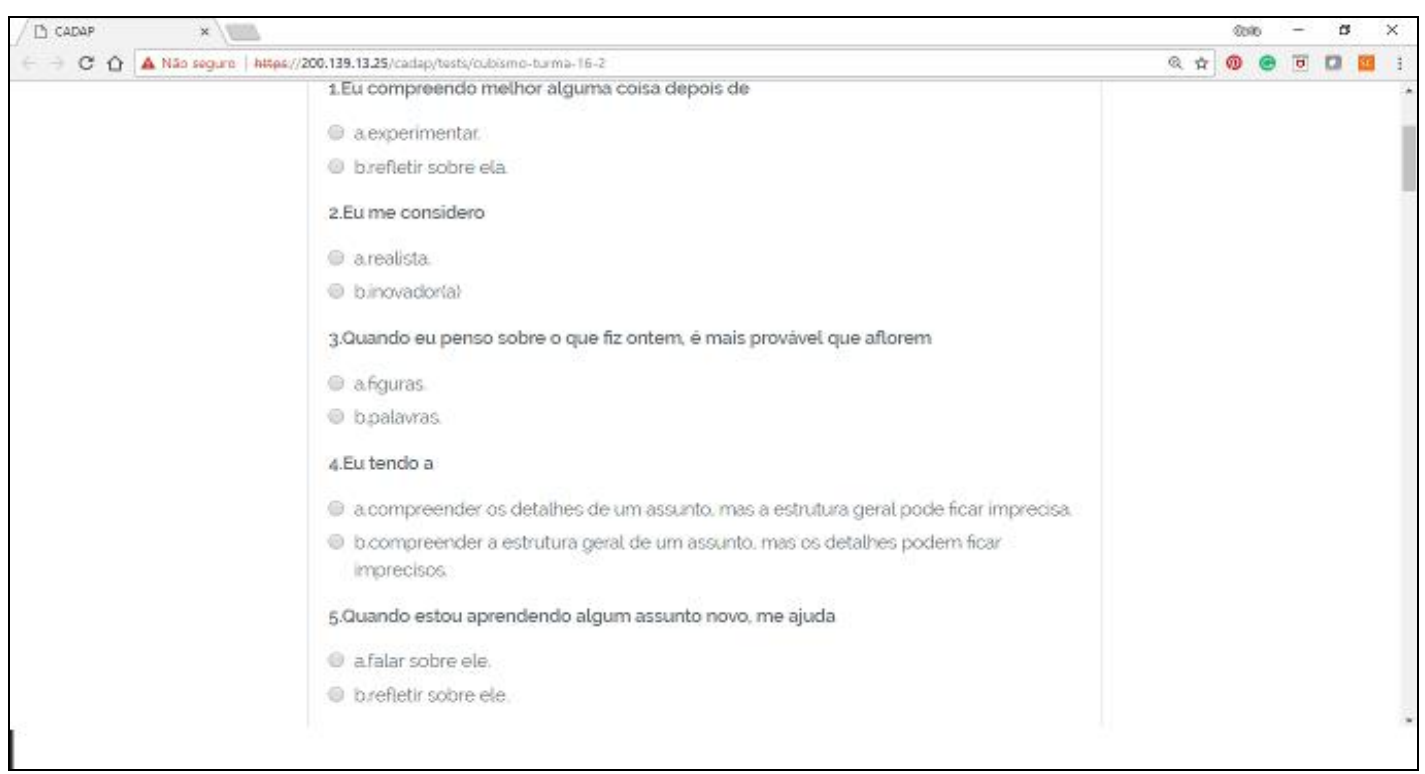

Figura 2. CADAP - Formulário de Felder e Sllverman

\subsection{2 - Modelagem dos Conteúdos Curriculares.}

Esta proposta prevê que os conteúdos curriculares utilizados, devem ser classificados quanto a abordagem utilizada: Baseada em Problemas, Baseada em Projetos, Palestras, com o objetivo de correlacionar os métodos de ensino, com os perfis de aprendizagem, as expressões faciais dos alunos durante a apresentação do conteúdo e o desempenho dos discentes. A ferramenta CADAP permite o registro dos conteúdos(aulas), com suas respectivas classificações.

\subsection{3 - Aplicação e Avaliação dos Conteúdos}

O núcleo da abordagem proposta neste trabalho é a utilização de uma ferramenta de captura e reconhecimento de expressões faciais durante as aulas e as avaliações de conteúdo. Esta ferramenta possibilita analisar as emoções dos alunos e correlaciona-las com fatores como perfil de aprendizagem do aluno, dispositivos de aprendizagem utilizado pelo professor e desempenho do aluno. Para que isto seja possível durante as aulas os alunos são filmados e a ferramenta captura e analisa as expressões faciais dos alunos em intervalos de tempos definidos pelo docente, e, assim constrói sua base de conhecimento dos alunos e de suas emoções. Ao final de cada aula o aluno preenche na própria ferramenta, um questionário (ver figura 3) em que avalia as emoções percebidas por ele durante as aulas, ponderando o quanto percebeu esta emoção entre muito fraco, fraco, mediamente, forte e muito forte. $\mathrm{O}$ objetivo deste questionário é possibilitar a comparação entre as emoções percebidas pelos alunos, com as emoções detectadas pela ferramenta. 


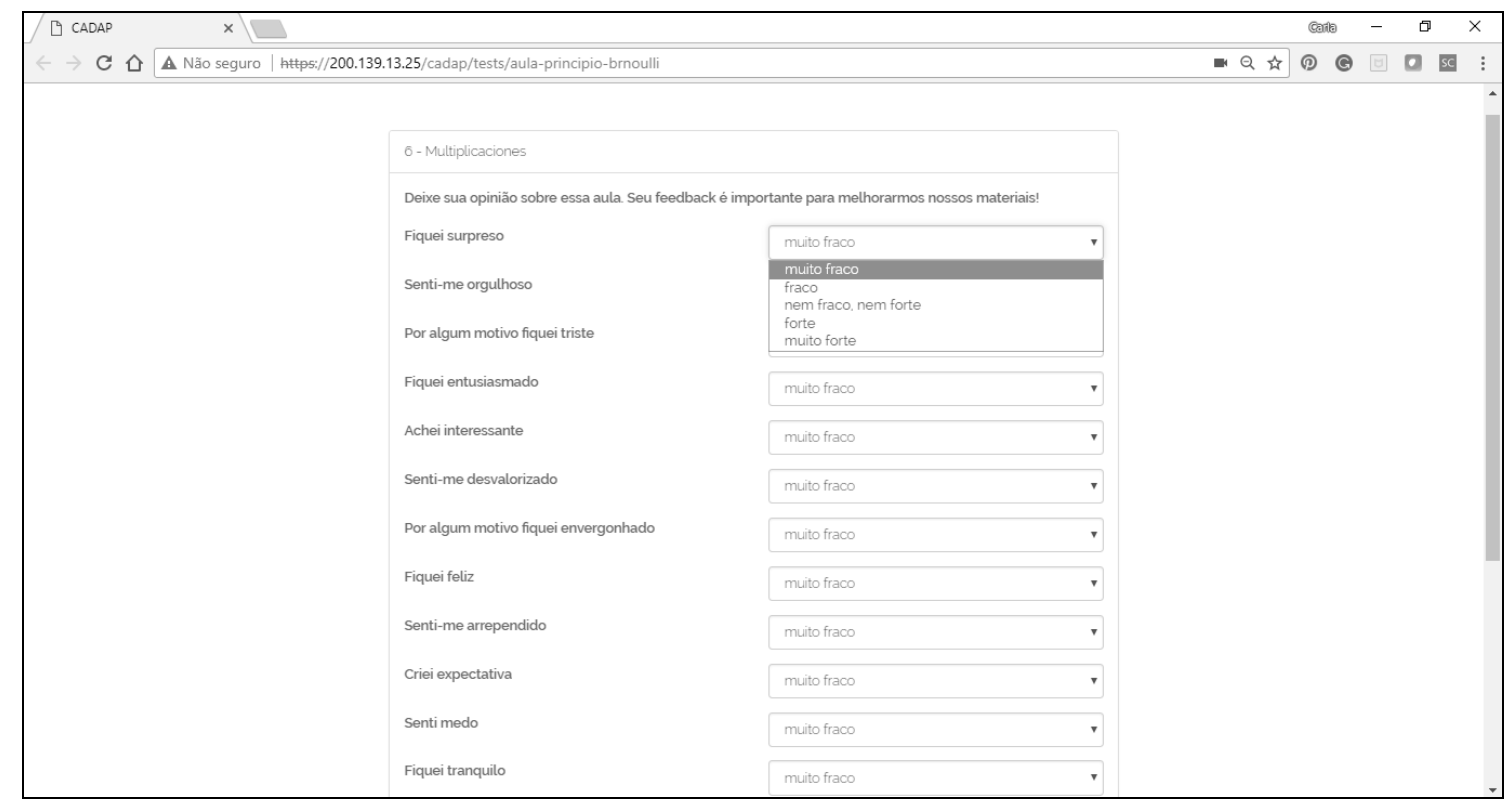

Figura 3. CADAP - Questionário de Emoções Percebidas pelos Alunos

\subsection{4 - Análise dos Resultados}

O objetivo principal desta abordagem metodológica é propor hipóteses e validá-las a partir dos dados coletados durante as aulas e avaliações, além de estabelecer correlações entre os elementos envolvidos no processo. A seguir exemplo de uma possível hipótese e correlação estabelecida a partir da utilização desta proposta.

Hipótese - "Quanto maior o tempo que um aluno permanece com expressões de alegria, a média da sua avaliação tende a aumentar"

Após a aplicação da metodologia hipóteses como esta podem ser validadas (ou não) agrupando os alunos por percentual do tempo que permaneceram com a expressão de alegria durante a aplicação dos conteúdos curriculares e avaliando o resultado destes alunos, assim verificando a hipótese de aumento da média conforme aumento do tempo que os alunos permaneceram com expressão facial de alegria.

\section{A Ferramenta CADAP}

A ferramenta CADAP foi desenvolvido em um contexto que visa estudar as relações entre as emoções do aluno, os dispositivos de aprendizagem, os conteúdos utilizados e a performance dos alunos. Neste contexto, a captação da emoção dos alunos pode ser feita de várias maneiras, batimentos cardíacos, expressões faciais, temperatura, entre outros. $\mathrm{Na}$ ferramenta, isso é feito através da captura das expressões faciais dos alunos. A figura 4 exemplifica esse contexto no qual o CADAP atua capturando as expressões faciais dos alunos durante as aulas e avaliações, armazenando estes dados em uma base de dados e posteriormente realizando análises que permitam estabelecer correlações entre perfil de aprendizagem dos alunos, dispositivos de aprendizagem utilizados, emoções registradas e desempenho dos alunos nas avaliações. 


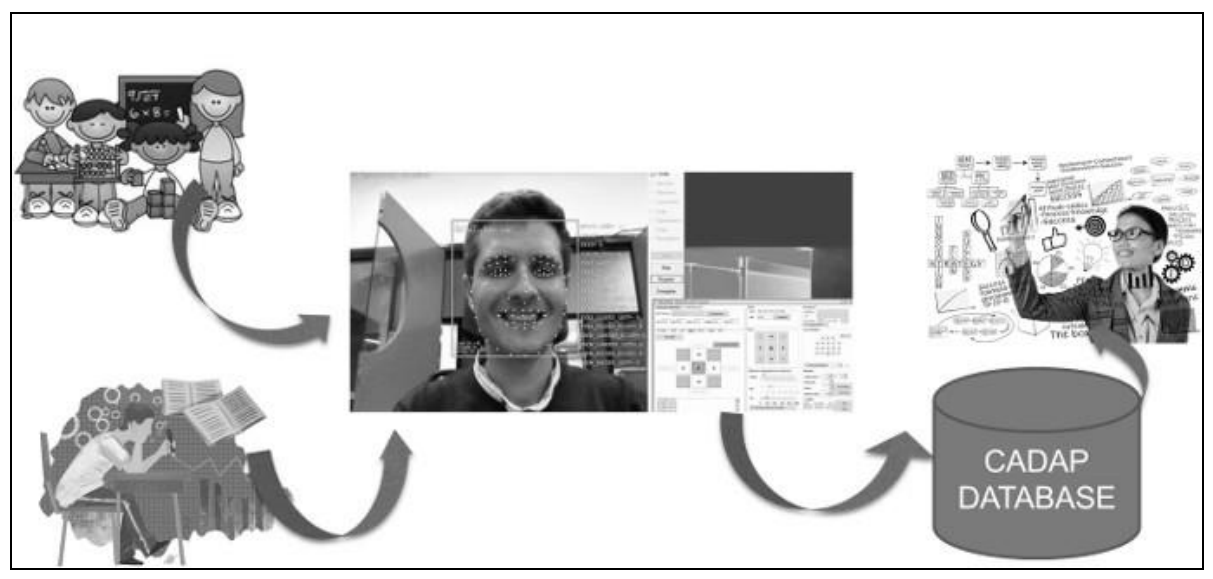

Figura 4. Metodologia CADAP

\subsection{Funcionalidades}

A ferramenta CADAP permite que sejam cadastradas aulas, turmas, avaliações para os alunos, bem como a visualização de aulas, com a respectiva captura de expressões faciais e emissão dos resultados, por aula e por turma. A figura 5 apresenta o diagrama de caso de uso com as principais funcionalidades da ferramenta disponíveis para o perfil de professor, sendo elas o cadastro de usuários, turmas, aulas e avaliações, bem como a visualização de resultados. Todas estas funcionalidades já estão implementadas na atual versão da ferramenta.

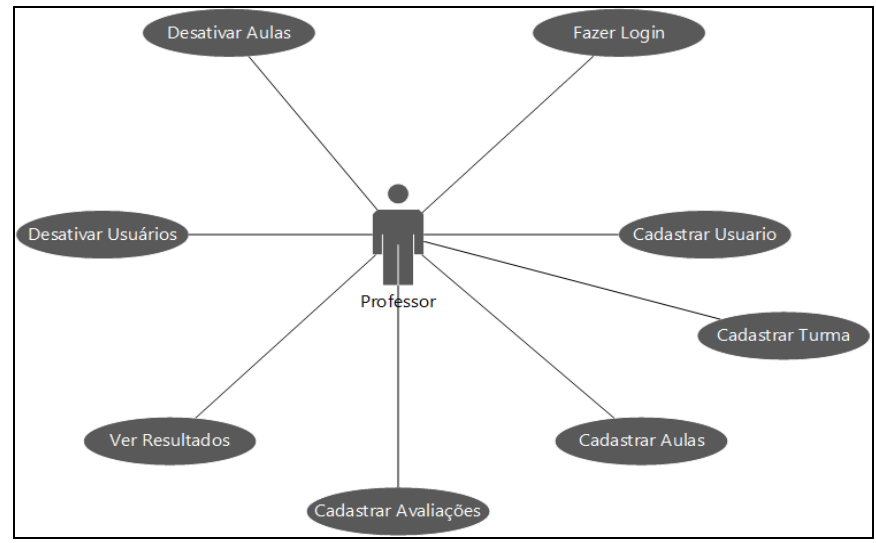

Figura 5. CADAP - Funcionalidades do Professor

A figura 6 apresenta a funcionalidade principal do CADAP que permite que as expressões faciais dos alunos sejam capturadas, enquanto estes assistem as videoaulas disponibilizadas na ferramenta. Nesta figura no menu superior direito é possível visualizar a imagem da face do aluno sendo capturada, enquanto este assiste aula na ferramenta. Ao finalizar a aula é gerado um relatório com as emoções que prevaleceram no aluno durante a aula visualizada. 


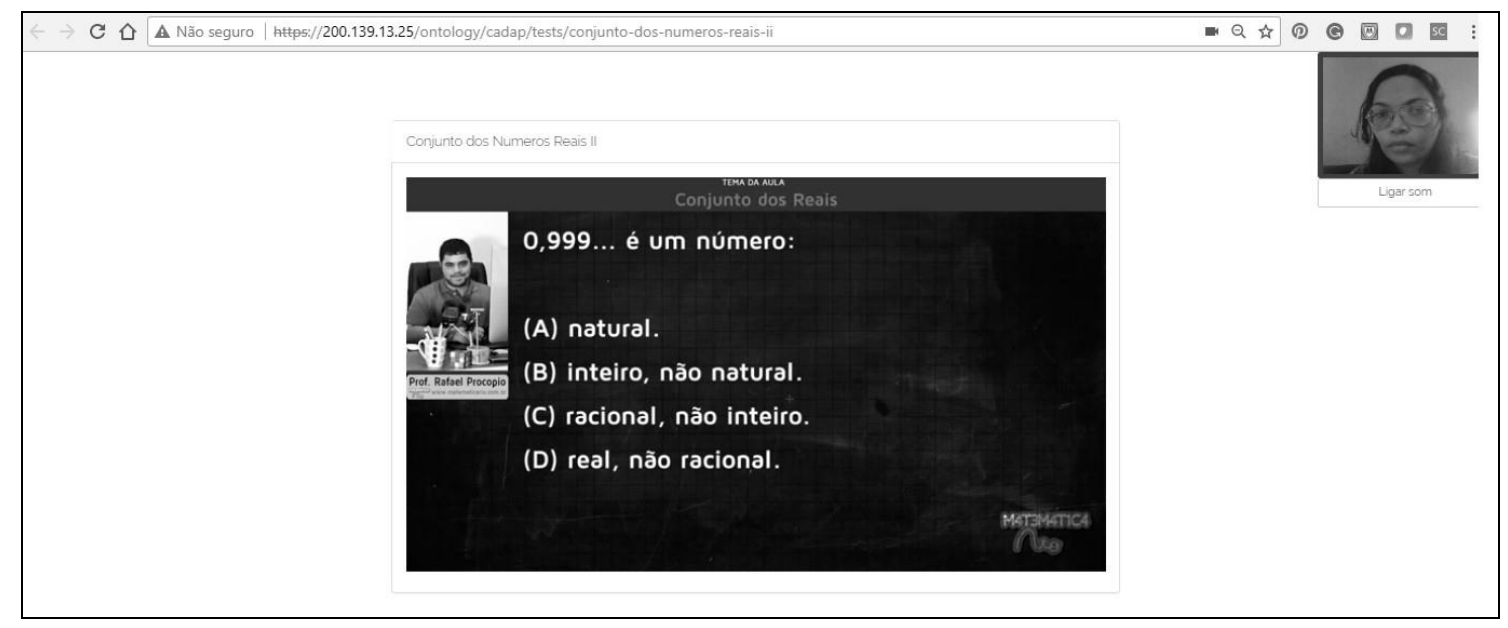

Figura 6. Tela de Visualização de Aulas e Captura de Expressões Faciais

A figura 7 mostra um gráfico gerado após o aluno assistir uma videoaula no CADAP. Neste gráfico é possível acompanhar a variação das sete emoções que a ferramenta analisa - alegria, tristeza, surpresa, medo, raiva, desgosto, desprezo e compromisso. Com isso é possível verificar o momento da aula que houve variação significativa de emoções, quais emoções prevaleceram durante a aula, se o desempenho do aluno está relacionado as emoções positivas e/ou negativas observadas no aluno durante a aula, dentre outras possíveis conclusões.

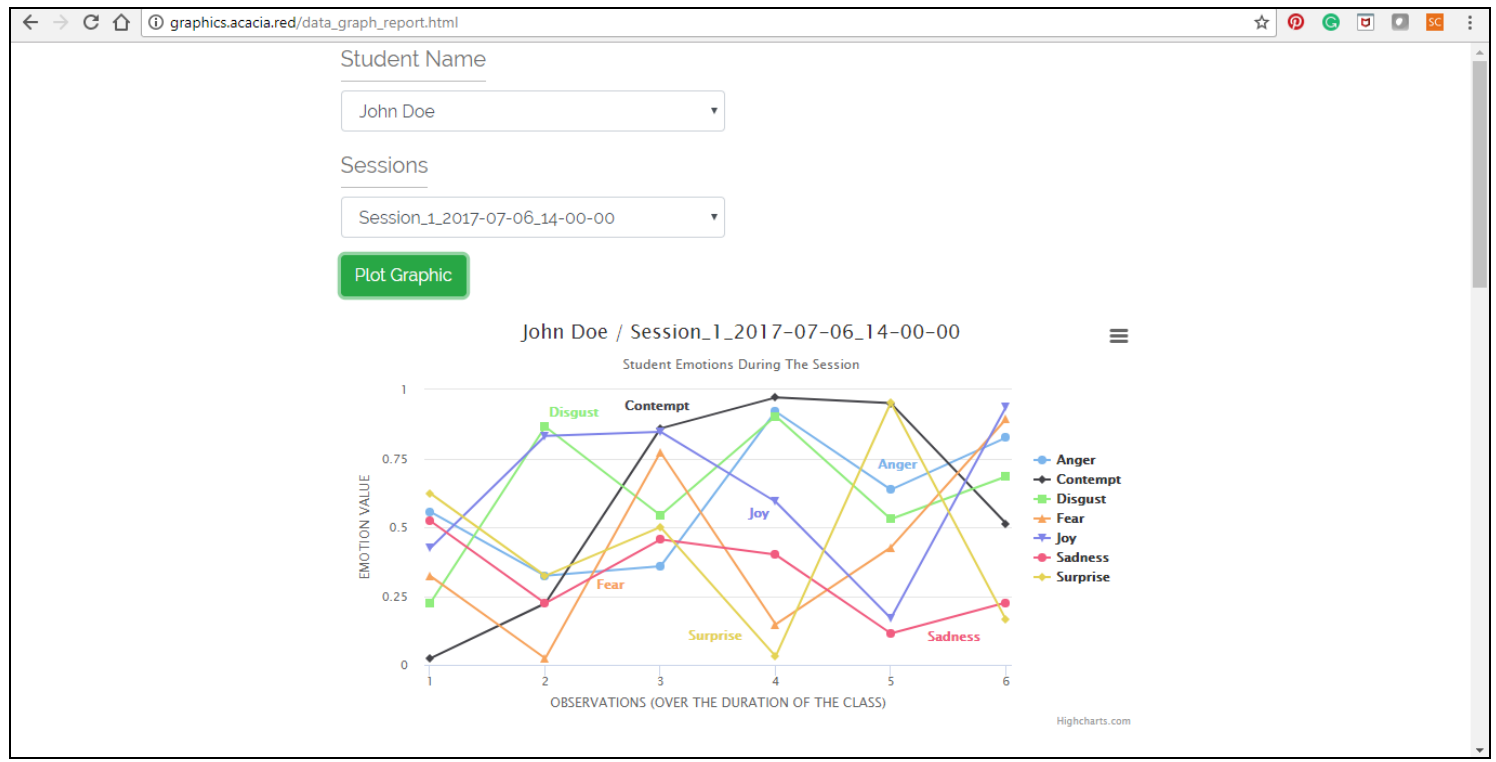

Figura 7. Gráfico de Variação de Emoções dos Alunos

\subsection{Componente de Análise de Expressões Faciais - Affectiva}

O rosto humano fornece uma tela rica para nossas emoções, pois estamos inatamente programados para expressar e comunicar emoção através de expressões faciais. A tecnologia desenvolvida pelo Affectiva [D. McDuff, 2013] identifica primeiro um rosto humano em tempo real ou em uma imagem ou vídeo. Os algoritmos de visão computacional identificam os principais pontos de referência no rosto - por exemplo, os 
cantos das sobrancelhas, a ponta do nariz, os cantos da sua boca. Os algoritmos de aprendizado de máquina então analisam pixels nessas regiões para classificar as expressões faciais. As combinações dessas expressões faciais são então mapeadas para as emoções. A tecnologia Affectiva mede sete métricas de emoção: raiva, desprezo, desgosto, medo, alegria, tristeza e surpresa. A tecnologia de reconhecimento emocional do Affectiva está disponível em vários produtos como SDK e API que podem ser acopladas em diversas ferramentas. No escopo deste trabalho a ferramenta CADAP acopla esta tecnologia para reconhecimento das expressões faciais dos alunos durante as aulas, pois acredita-se que as métricas de engajamento e atenção obtidas pela ferramenta são indicadores fundamentais de compreensão dos alunos, permitindo uma intervenção precoce para melhorar a retenção de conteúdo.

\section{Discussão de Resultados}

Estão sendo realizados vários experimentos de utilização da ferramenta, onde os docentes preparam aulas e disponibilizam na ferramenta CADAP para que os alunos assistam e suas emoções sejam monitoradas. Estes experimentos estão sendo realizados em diferentes áreas do conhecimento, como eletrônica digital, química, literatura, entre outros com objetivo de analisar diversos cenários. A Figura 8 apresenta um destes experimentos. Baseado nestes cenários, análises estão sendo feitas para que a ferramenta possa auxiliar em medições como apresentadas nas próximas seções;

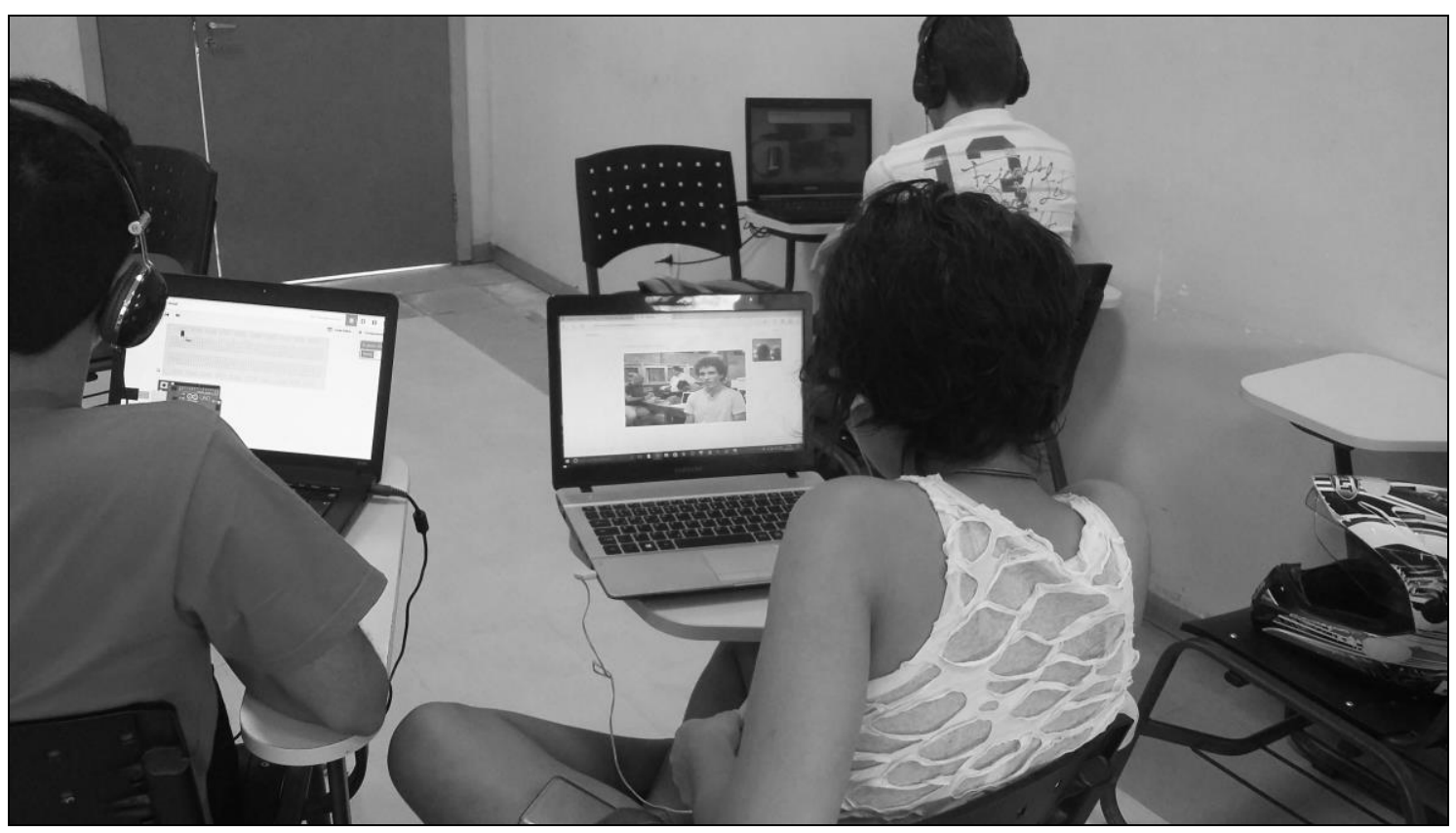

Figura 8. Experimento de Utilização do CADAP

\subsection{Desempenho de Aluno por Aula}

Com os dados gerados pela ferramenta é possível analisar a média de emoções positivas e negativas de cada aluno nas aulas e posteriormente correlacionar estas informações com as avaliações realizadas sobre os assuntos tratados nas aulas. 


\subsection{Acompanhamento das Emoções da Turma}

A ferramenta permite analisar a média das emoções dos alunos durante as aulas, possibilitando aos docentes saberem se os objetos de aprendizagem utilizados na disciplina despertam emoções positivas ou negativas nos alunos. No exemplo da figura 8, após a utilização da ferramenta na aula de literatura, com tema futurismo, é possível ao docente saber que esta aula despertou um maior percentual de emoções positivas como alegria e surpresa.

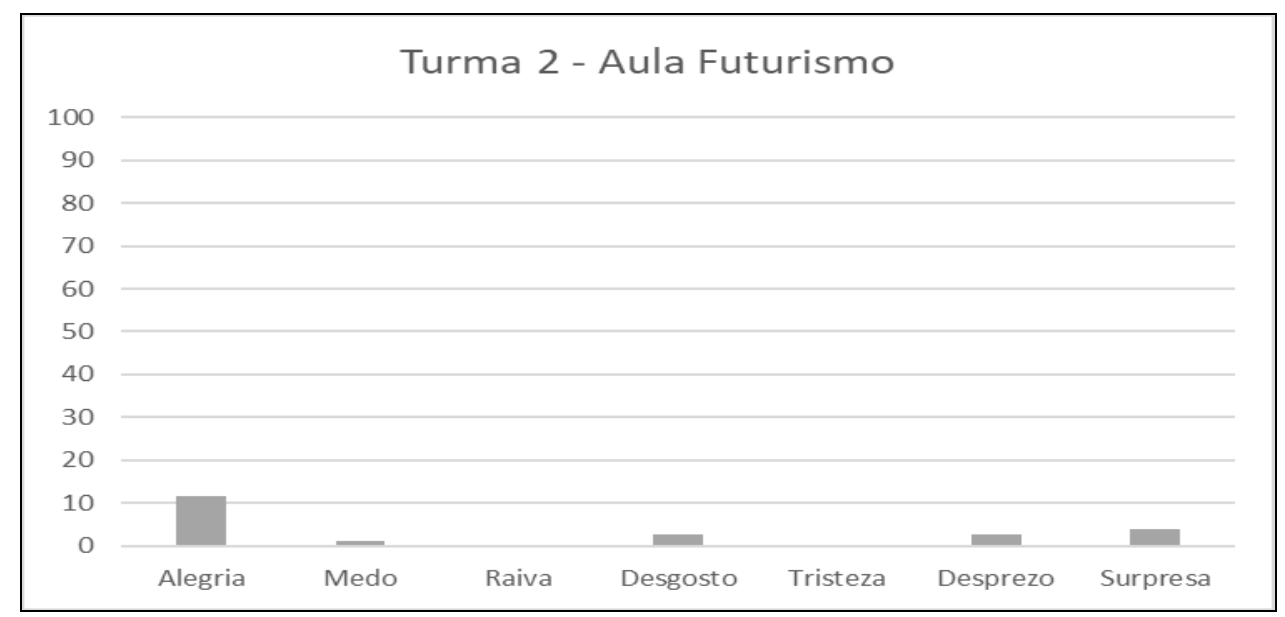

Figura 8. Acompanhamento de Emoções da Turma

\subsection{Acompanhamento Individual dos Alunos}

Baseado nos dados coletados pela ferramenta, é possível analisar a variação individual das emoções dos alunos, e com isso, o docente pode verificar como cada aluno reage ao conteúdo aprendizado e analisar as possíveis causas de variação de emoções para cada aluno. Sabe-se que a variação das emoções dos alunos, nem sempre estarão relacionadas ao ambiente de aprendizagem, pois o aluno pode já estar com estado emocional afetado por outras condições externas, porém a ferramenta pode auxiliar o professor a identificar estas situações. Um aluno que mesmo com a variação de conteúdos e objetos de aprendizagem sempre permanece com um determinado estado emocional, tristeza por exemplo, pode estar passando por alguma dificuldade, e a utilização de uma ferramenta como a proposta neste trabalho, pode ajudar ao professor a perceber esta situação.

\section{Considerações Finais e Trabalhos Futuros}

Neste artigo, foi apresentada uma ferramenta que utiliza as emoções do aluno para apoiar o processo de ensino-aprendizagem. As expressões faciais do aluno são coletadas automaticamente utilizando esta ferramenta de reconhecimento de expressão facial CADAP - e posteriormente estas expressões são interpretadas e classificadas em sete emoções básicas, alegria, tristeza, desgosto, surpresa, raiva, medo e desprezo. As emoções detectadas servirão de base para estabelecimento de correlações entre emoções, dispositivos de aprendizagem, metodologias de ensino e desempenho dos estudantes, para isto serão implementados métodos de deep learning para investigação mais profunda destas correlações. Atualmente estão sendo realizados experimentos em disciplinas utilizando esta ferramenta com objetivo de validar metodologia e coletar 
dados para futuras análises. A intenção da ferramenta é possibilitar aos docentes conhecer as emoções despertadas por suas aulas, para as turmas e para cada aluno possibilitando aos docentes correlacionar estas informações e atuar quando for necessário, ajustando seus conteúdos e apoiando os discentes individualmente no seu processo de aprendizagem.

\section{Agradecimentos}

A Universidade Federal do Oeste do Pará e ao Projeto ACACIA pelo apoio e suporte financeiro ao desenvolvimento deste trabalho.

\section{Referências}

Damasio And a. Descartes, Error: emotion, reason, and the human brain. New york:1994.

D. McDuff, R. El Kaliouby, T. Se nechal, M. Amr, J. F. Cohn, and R. Picard. Affectivamit facial expression dataset (AM-FED): Naturalistic and spontaneous facial expressions collected" in-the-wild". In Computer Vision and Pattern Recognition Workshops (CVPRW), 2013 IEEE Conference on, pages 881-888. IEEE, 2013.

Dolog, Peter And Shaefer, Michael. A Framework for Browsing Manipulating and Maintaining Interoperable Learner Profiles. Proceedings of UM2005 - 10th International Conference on User Modeling, Springer Verlag, United Kingdom, 2005 .

Ekman, P. And Friesen W. V. Facial Action Coding System. Palo Alto: Consulting Psychologists Press, 1978

Felder, Richard And Silverman, Linda K. Learning and Teaching Styles in Engineering Education. Engineering Education, vl. 78, n. 7, pp674-681. 1988

Izard, c. Emotion-cognition relationships and human development. In: izard, c.1984;

Lee, Catherine $\mathrm{H} \mathrm{M}$ et al. What affect student cognitive style in the development of hypermedia learning system? Computer and Education, vl. 45, n.1, pp 1-19, 2005.

Mora, Francisco. NeuroEducación, Solo se puede aprender aquello que se ama. Madri, 2013.pp 65-72

Piaget, Jean. A psicologia da criança. 17ed. Rio de Janeiro: Bertrand Brasil, 1989

Picard, r. Affective computing. Cambridge: mit press, 1997. 262 p.

Vygotsky, 1. The problem of the environment. In: veer, r. V.; vlasiner, j. (ed.). The vygotsky reader. Cambridge, ma: blackwell, 1994. P. 338-354 